ESTUDOS LINGÜÍSTICOS 


\title{
TOWARDS A MORE SYSTEMATIC TEACHING OF THE SUPRASEGMENTAL LEVEL OF SPEECH
}

\section{Rosana de Albuquerque Sá Brito *}

\begin{abstract}
Although the supmsegmental level of speech has gained importance among recert sciertific research, several problems still seem to render it difficult for the forign language teacher to prioritize prasody in the L2 curriculum. In this article we discuss some of these problems, at the same time as we suggest aspects of prasady to be included in $L 2$ pronunciation syllabuses in universities.
\end{abstract}

L

anguage majors in universities are often expected to acquire the target language to be able to use it, and at the same time learn about its usage to be able to teach it. It seems evident, however, that a complete language, and all its subtleties, cannot possibly be taught within the short time available. In the case of English at Universidade Federal do Paraná, for example, students are expected to graduate in about 4 years, and most of the contact they have with the English language takes place inside the classroom during regular course hours. For this reason the professors must select teaching content following some practical criteria. Although a final selection of specific items can only be considered after students' actual needs and abilities have been analyzed, it seems possible to establish some sequencing of the components of pronunciation in an attempt to promote intelligibility.

Contemporary research has been able to establish the importance of the suprasegmental, or prosodic, level of speech by providing evidence that languages could be identified by intonation alone (Gilbert, 1980). Traditionally viewed as dessert for the end of the L2 courses, the suprasegmental

* Universidade Federal do Parana 
domain seems to have assumed a prominent position in discussions about I2 pronunciation teaching over the last decades. Johanssohn (1978), and Anderson-Hsieh and Koehler (1988) state that prosodic interference may be more harmful to communication than phonemic interference since segmental errors are found to cause a lower degree of deviance than suprasegmental ones. Abberton et al. (1978) argue that prosody should precede segmental phonology since prosodic features provide the essential framework for the realization of segments.

With reference to listening comprehension, Loveday (1982) observes that native listeners' intelligibility of an utterance is not highly dependent upon the speakers' phonetic accuracy. Dirven and Oakshott-Taylor (1984) also attest the greater importance of suprasegmental features to comprehension:

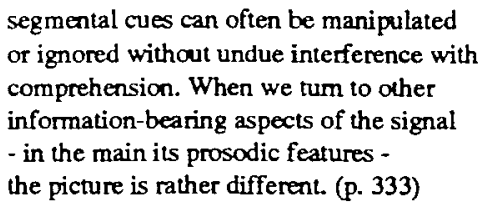

Gilbert (1987) not only emphasizes the importance of suprasegmentals to communication: "the most powerful signals in spoken English are expressed by intonational devices: pitch patterns and timing" (p. 33), but also asserts that by concentrating class time on the systematic teaching of those devices - which she calls the most important elements of pronunciation - both listening comprehension and pronunciation skills can be improved.

Despite all these arguments many ESL teachers still seem rather reluctant before the idea of prioritizing prosody in their pronunciation programs. Whereas phoneme, allophone, minimal pair, are all concepts which, at least apparently, can be readily grasped and easily taught, explanations about suprasegmental features are not always so tangible. In addition, ESL teachers often face even terminological barriers which tend to difficultate the introduction of recent trends on pronunciation teaching into the L2 curriculum. For example, in studies about English pronunciation the suprasegmental level is usually associated with the concepts of stress and intonation; Brown et al. (1980), however, focus attention on the fact that 


\author{
is confused and confusing. $[. .$.$] In her$ \\ extensive study of suprasegmentals in \\ speech, Lehiste (1970) ranges widely \\ across the descriptive, instrumental and \\ experimental literature in order to try \\ to discem a principled means of \\ distinguishing stress from intonation, \\ and encounters the familiar difficulties. (p. 31)
}

In their own discussion of the concepts, Brown et al. prefer to take a "high-handed" approach assuming that "stress is a property of words and that intonation is a property of utterances." (p. 31)

Traditionally, attempts to identify the nature of stress have considered either the listener's or the speaker's standpoint. Thus, whereas one definition may mention a greater intensity or loudness perceived as a consequence of different amplitudes of sound waves (Bloomfield, 1984), another may refer to a stronger force produced by the muscles (Jones, 1975). In an examination of the mechanisms believed to be associated with stress, Adams (1979) found no correlation between this phenomenon and internal intercostal muscular activity. Her investigations of the acoustic parameters associated with this feature revealed that duration was the most frequent used cue, and that both frequency and amplitude were also employed to signal stress. In more recent years the metrical approach developed within generative phonology has regarded relational auditory prominence as a crucial fact to the concept of stress. Katamba (1989) emphasizes that stress is "essentially a perceptual phenomenon, with ill-defined articulatory correlates" (p. 221). The author also observes that stressed syllables have higher pitch, longer duration, and, less importantly, are louder than their unstressed counterparts.

With respect to intonation, Brown et al. (1980) call the reader's attention to the differences in the terminology used by linguists to refer to certain phonetic entities:

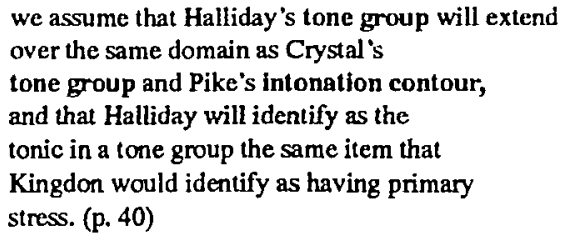

Despite the constraints mentioned above, it seems necessary to 
include suprasegmental features in the teaching of a second or foreign 'anguage, due to their relevance to communication. Among the most important aspects of prosody, the teacher must try to show his/her students the functions realized by different intonation patterns in actual communication. As Brazil et al (1980) point out, intonation choices not only indicate the structure of discourse and distinguish between new and given information, but also provide clues as to whether the participants do or do not share the same point of view about a certain topic or particular information. Sometimes intonational features are sufficient to provide for information, perform certain illocutionary acts, obtain confirmation or denial, resolve ambiguity, etc.; other times they may be associated with paralinguistic features such as gestures and facial expressions in order to reveal the speaker's attitude.

In order to facilitate intelligibility and to avoid unfavorable social judgements against the $\mathrm{L} 2$ speaker, it is also suggested that specific teaching of voice quality settings should be included in the phonology component of the L2 curriculum. Such settings are general articulatory features of speech which characterize a particular language, dialect, social group, etc. Laver (1980) refers to them as "phonetic settings", and describes them as "a quasi-permanent tendency" of speakers to adopt certain habitual articulatory postures which convey an "auditory coloring" throughout speech. According to Esling (1982)

\author{
a teacher's awareness of differences in voice \\ quality and an ability to present features of \\ pronunciation in terms of the long-term \\ configurations of the vocal tract musculature \\ can be economical for leaming and beneficial \\ to the students' performance in spoken English. (p. 6)
}

He also observes that differences in the voice quality settings between the native and the target language will cause long-term interference and may reduce intelligibility. Esling suggests that a student's different pronunciation problems may be the result of his/her inability to recognize one single feature of voice quality. Consequently the teacher can try to improve the student's pronunciation of a large number of lower-level segmental features by providing instruction on a relatively small number of higher-level articulatory postures which constitute voice quality setting.

It must be pointed out, however, that voice quality settings do not characterize only particular languages but also specific dialects, social 
groups, and even individual speakers. In this way, selection of specific settings have implications concerning the choices of varietics. As a general model, Esling and Wong (1983) provide a list of features that are common to a wide variety of North American English speakers: spread lips, open jaw, palatalized tongue body position, retroflex articulation, nasal voice, lowered larynx, creaky voice. It is believed that a traditional segmental approach may not be an efficient way of introducing pronunciation in a second language. Esling and Wong's contention is that by emphasizing segmental features, as in the presentation of minimal pairs, ESL pronunciation teachers tend to make it more difficult for students to identify the importance of higher-level features for general communication in the target language. As an alternative approach it is recommended that students should first be made aware of settings both in their native language and in the target one.

Having students with different regional accents present short phrases or tongue-twisters to the rest of the class is suggested as an effective technique to help students recognize dialectal features as well as general higher-level postures in the native language. An easy introduction to the L2 general setting would be to ask students to imitate an English-speaker trying to speak, for example, Portuguese; this activity could provide students with colorful examples of the habitual positions of articulation in the $\mathrm{L} 2$ connected speech. It would be also greatly desirable, even though not always attainable, to enrich students knowledge of voice quality settings by presenting them instances of degrees of prestige as represented by different varieties of English. With advanced groups this procedure could help sharpen students: ability to make more accurate judgements about oral input as well as enable them to evaluate the image they may project of themselves when speaking the target language.

It follows that a contrastive analysis between voice quality settings in the native and in the target language would be a useful tool for the L2 teacher. As with other aspects of language, the features of a setting associated with higher prestige in, say, English may not correspond to the voice-setting features that students bring from, say, Portuguese. In this case, awareness of the differences may help avoid unfavorable social judgements as well as increase intelligibility.

Besides the general characteristics of English speech mentioned above, the teacher may realize that the ESL program must account for some specific phenomena in order to equip the learner with the minimum phonological tools required to facilitate comprehension and production of the target language. These might include aspects such as reductions of 
function words versus the use of full forms; lengthening, reduction, and loss of phonemes; different kinds of assimilation; variation in pitch level; etc. The learner may also be made aware of other subtleties of speech, as for example, the important role played by context in most of these processes. The student may learn to recognize, for instance, that pitch range is highly determined by the speaker's emotional state at the moment of the utterance, and that it consequently provides the listener with valuable clues about the communicative context.

Time should also be devoted to the teaching of processes of connected speech, such as linking and deletion, which help students understand and produce fluent English. Temperley (1987) points out that explicit teaching of these features is essential for the achievement of an acceptable level of intelligible pronunciation, since as learner's fluency develops words may become linked in non-English ways. Even though some teachers tend to consider linking and deletion as potentially postponable features in the ESL program, we strongly suggest their inclusion in introductory courses. As Temperley stresses

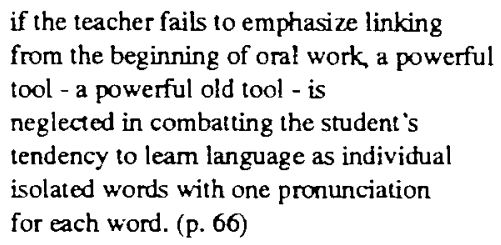

Of course the level of students"accuracy in pronunciation which is going to be targeted by the teacher will greatly determine the choice of features of speech that are going to be given prominence in the course.

We concede, however, that ESL teachers may feel uncertain about the rules governing linking and deletion, as well as about many aspects of the suprasegmental level of speech, since most pronunciation manuals usually lack adequate descriptions of such features. Our contact with ESL teaching professionals has allowed us to infer that many non-native English teachers find it hard, for example, to figure out what, say, a particular intonation contour expressed by written symbols of notations would actually sound like when uttered by a native speaker. At the same time the literature on the subject shows that even trained phoneticians and native speakers are sometimes unable to perceive intonation correctly (de Bot and Mailfert, 1982). Although the difficulties persist, we believe it essential to move 
towards a more systematic teaching of the suprasegmental level and general features of connected speech, particularly to students majoring in foreign languages. It is now the task of linguists, applied linguists, and university professors and researchers to seek for answers to the various problems placed before us.

\section{BIBLIOGRAPHICAL REFERENCES}

ABBERTON, E., PARKER, A., and FOURCIN, A. (1978). Speech improvements in deaf adults using laryngograph displays. Speech and Hearing Work in Progress, (p. 33-60). University College of London, Department os Phonetics and Linguistics.

ADAMS, C. (1979). English speech rhythm and the foreign learner. The Hague, Mouton.

ANDERSON-HSIEH, J. and KOEHLER, K. (1988). The effect of foreign accent and speaking rate on native speaker comprehension. Language Learning, 38, 561-613.

BLOOMFIELD, L. (1984). Language. Chicago: The Unviersity of Chicago Press.

DE BOT, K. and MAILFERT. K. (1982). The teaching of intonation: fundamental rescanch and classroom applications. TESOL Quarterly, 16, 71-77.

BRAZIL, D., COULTHARD, M. and JOHNS, C. (1980). Discourse intonation and language teaching. London: Longman.

BROWN, G. CURRIE, K. Land KENWORTHY, J. (1980). Questions of Intonation. Baltimore: University Park Press.

DIRVEN, R, and OAKESHOTT-TAYLOR, J. (1984). Listening comprehension (Part I). Language Teaching, 17, 326-343.

ESLING, J.H. (1982). Suggestions for confronting pronunciation in ESL. TEAL Occasional Papers, 6, 3-9.

ESLING, J.H., and WONG, R.F. (1983). Voice quality settings and the teaching of pronunciation TESOL Quarterly. 17, 89-95.

GILBERT, J.B. (1980). Prosodic development: some pilot studies. In Scarcella and S. Krashen (eds.), Research in second language acquisition, (p. 110-117). Rowley: Newbury House.

GILBERT, J.B. (1987). Pronunciation and listening comprehension. In J. Morley (ed.), Current perspectives on pronunciation: Practices anchored in theory, (p. 29-39). Washington, D.C.: TESOL.

JOHANSSOHN, S. (1978). Studies of crror gravity. Collection Gothenburg Studies on English, 44, 78-118.

KATAMBA, F. (1989). An Introduction to phonology. New York: Longman.

LAVER, J. (1980) The phonetic description of voice quality. Cambridge: Cambridge University Press.

LEHISTE, I. (1970). Suprasegmentals. Cambridge: The MIT Press.

LOVEDAY, L. (1982). The sociolinguistics of learning and using a non-native language. Oxford: Pergamon Press.

TEMPERLEY, M.S. (1987). Linking and delection in final consonant clusters. In J. Morley (ed.). Current perspectives on pronunciation: Practices anchored in theory. (p. 59-82). Washinglon, D.C.: TESOL. 